Journal of Applied Fluid Mechanics, Vol. 4, No .1, pp. 121-138, 2011. Available online at www.jafmonline.net, ISSN 1735-3572, EISSN 1735-3645. DOI: $10.36884 / \mathrm{jafm} .4 .01 .11909$

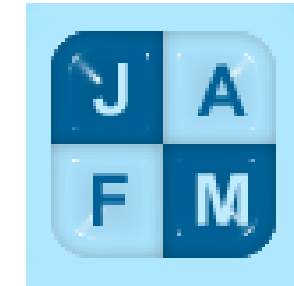

\title{
The Fire Simulation in a Road Tunnel
}

\author{
M. J. Jafari ${ }^{1}$, A. Karimi ${ }^{2}$, A. E. Usachov ${ }^{3}$ and H. Kanani Moghaddam ${ }^{4}$ \\ ${ }^{l}$ Occupational Health Dept, Faculty of Health, University of Shahid Beheshti (MC), Tehran, Iran \\ ${ }^{2}$ Occupational Health Dept, School of Public Health, Tehran Med Sci University, Tehran, Iran \\ ${ }^{3}$ Industrial Aerodynamics Dept, Aerospace Research Centre, Moscow, Russia \\ ${ }^{4}$ Laniz Consulting Engineers Company, Tehran, Iran
}

Email: Jafari1952@yahoo.com

(Received September 3, 2008; accepted February 5, 2010)

\begin{abstract}
Fire behaviour, especially its interaction with ventilation system in tunnels, is still a challenging issue for road tunnel designers .This paper presents the results of a study investigating the influence of a road tunnel ventilation system, on conventional fires. For this purpose, a $25 \mathrm{MW}$ fire corresponding to a conventional fire in a road tunnel was simulated using 2D numerical modelling, for transient viscous multi-component gas at low Mach numbers to study smoke and heat propagation within a road tunnel under fire .Complete Navier-Stocks and Reynolds equations were solved using developed algorithm of numerical modelling. The results from a series of calculations were compared with results of experimental researches to examine the accuracy and stability of the calculations. The comparisons showed that the algorithm provided a good description of physical processes in selected class of flow. It was also concluded that calculation accuracy is not lower than those obtained from established simulation software programs . The stability and good convergence of the algorithm was confirmed by separate calculations with different grid patterns for the tunnel under consideration. The results revealed that the temperature at tunnel wall may rise up to $900^{\circ} \mathrm{C}$. The concentration of smoke may also increase up to $95 \%$ with a burning truck .Results were applied to assess the ventilation system designed for a new long road tunnel in case of fire. The results from the study along with other information were applied to assess the designed ventilation system and to establish the suitable fire fighting and rescue plan .
\end{abstract}

Keywords: Ventilation, system, numerical analysis, safety

\section{INTRODUCTION}

The objective of fire and smoke control in tunnels is to minimize casualties and structural damage .Appropriate ventilation design and management are important for achieving these objectives. Both theoretical and experimental investigations on fire and smoke behaviour started many years ago .In 1985, Kumar and Cox (1985) published a mathematical model of fires in road tunnels. Since then, many studies have been reported on numerical simulation of fire in tunnels (Chow and Leung 1988; Kumar and Cox 1988; Kawabata, Ohashi et al. 1991). Experimental studies of small and full-scale fire tests have also been reported by many authors .Jafari (1997) lists some of them (Jafari 1997) The Memorial Tunnel fire data, are the most recent with substantial experimental data relating to it (Bendelius 1997; PIARC 1999; Kuriokaa, Oka et al. 2003; Lonnermark and Ingason 2005). In last two decades 3D and 2D numerical simulation based on Computational Fluid Dynamics (CFD) of fire has been of particular interest to many researchers (Biollay and Chasse 1994; Rhodes 1994; Rhodes 1996).

The need to validate numerical methods against results in full scale tunnels has been recognised since 1991 .
Some of these methods have been validated against experimental data (Kawabata, Ohashi et al. 1991; Malalasekera and Lockwood 1991; Simcox, Wikes et al. 1992; Biollay and Chasse 1994) while some have failed (Bettis, Jagger et al. 1994) .

Appropriate ventilation design for smoke control has been in existence for a long time. PIARC (Permanent International Association of Road Congresses) has its own recommendations for ventilation, (Lacroix 1994; Lacroix and Arditi 1996). The throttling of air, i.e the rapid expansion of air as it is heated by fire, is a key design consideration in longitudinal ventilation; and the possibility of damage to jet fans located close to the fire point due to heat requires to be considered, (Bendelius 1996; Lacroix 1996).

Mathematical models based on CFD can be used in the assessment of fires in road tunnels as a means of explicitly ensuring that the ventilation systems for new road tunnels will act satisfactorily in case of a fire in the tunnel. The need for development of temperature and smoke prediction method stems from evermore stringent safety regulations and a desire to avoid the worst consequences of major accidents and large fires 
in a real tunnel. Rhodes (1996) explains the advantages of fire and smoke simulation (Rhodes 1996) .

In the present study, equations for the conservation of fluid momentum and energy were solved to predict the flow behaviour within the region of interest .Since it is not feasible to solve chemical kinetics equations of combustion for such large-scale modelling, it is common practice to supplement the mathematical model with experimental data to describe the burning process .In this study, experimental data of PIARC (1999) were used to describe a conventional $25 \mathrm{MW}$ fire .The data correspond to burning of a heavy truck, loaded with combustibles. In the numerical modelling the airflow near the burning vehicle, temperature field and smoke spreading were calculated without consideration of chemical reactions.Thus, the temperature of vehicle surface and smoke released per second were assigned constant values as deduced from the PIARC data.

The tunnel in this study called Taloon tunnel consists of two tubes .West tube has $+1.63 \%$ and east one $-1.63 \%$ gradient .The length of each tube is 6350 meter which is divided into 10 sections. The length of each section is almost 600 meter.

Smoke and temperature along a tunnel section with traffic passing at different speed (e.g. 10 and $60 \mathrm{~km} / \mathrm{h}$ ) were simulated .Unidirectional and bidirectional traffic were considered in a 2-lane traffic tunnel for the different ventilation modes considered in the fire simulations:

Mode 1: Normal ventilation mode before fire detection signal from a dispatcher. The duration of this mode is 3 $\min$.

Mode 2: Ventilation during evacuation of people .In this mode, Fresh air is supplied from nearest two cross headings to provide evacuation of people .The duration of this mode is based on a pedestrian speed of $5 \mathrm{~km} / \mathrm{h}$. For a distance of $600 \mathrm{~m}$ between cross-headings the time for people to leave a danger zone will be $10 \mathrm{~min}$.

Mode 3: Smoke extraction mode .In this mode fans in two nearest cross headings will be switched to reverse their operating direction, and air will be extracted from the tunnel section suffering fire.

Based on the above assumptions, two central parts of the West and East Tunnels were chosen and test run to calculate smoke and heat spreading along the tunnel. Numerical modelling was conducted for 2D transient viscous multi-component gas at low Mach numbers . Experimental data from PIARC (1999) were used for smoke source and temperature location.

\section{Material AND MeTHOD}

Mass conservation, momentum, heat and heated gas transport equations for low velocities were used for numerical simulation. These equations are briefly given here.

Continuity equation :This equation for gas mixture may be written in the form of:

$$
\frac{\partial \rho}{\partial t}+\operatorname{div} \rho \vec{u}=0
$$

Where $\rho$ is the gas density and $\vec{u}$ is the velocity.

For multi-component gas mixture of $\mathrm{N}_{\mathrm{K}}$ components, the continuity equation must be written for each component:

$\rho \frac{\partial c_{i}}{\partial t}+\rho \vec{u} \frac{\partial c_{i}}{\partial \vec{r}}+\frac{\partial}{\partial \vec{r}} \vec{J}_{i}=w_{i}$

Here $c_{i}=\rho_{i} / \rho$ is the mass concentration of component $i$. $\vec{J}_{i}$ and $w_{i}$ are diffusion flux and mass creating rate of the component .

An approximation is used for expressing diffusion flux based on the kinetic theory of gases:

$\vec{J}_{i}=\rho c_{i} \vec{V}_{i}=\sum_{j=1}^{N_{k}} \frac{m_{i} m_{j}}{m^{2}} D_{i j} \vec{d}_{j}-D_{i}^{T} \frac{\partial \ln T}{\partial \vec{r}}$

Where,

$\vec{d}_{j}=\operatorname{grad} c_{j}+\left(x_{j}-c_{j}\right) \operatorname{grad} \ln p-$

$-\frac{c_{j}}{P}\left(\rho \vec{F}_{j}-\sum_{i=1}^{N_{k}} \rho_{i} \vec{F}_{i}\right)$

In Eqs. (3) \& (4) $m_{j}$ and $X_{j}=n_{j} / n$ are, respectively, the molecular weight and a molar concentration of $j$-th component, $\quad m=\left(\sum_{i=1}^{N_{k}} \frac{c_{i}}{m_{i}}\right)^{-1}-$ the molecular weight of the gas mixture, $p$ - static pressure, $\vec{F}_{j}$ vector of volume force density (for gravitational forces $\vec{F}_{j}=\vec{g}$-gravitational acceleration). Parameters $D_{i j}$ are the multi-component diffusion coefficients .They may be calculated from the system of linear equations:

$\sum_{\substack{j=1 \\ j \neq i}}^{N_{k}}\left(\frac{x_{i} x_{j}}{D_{i j}^{b}}+\sum_{\substack{n=1 \\ n \neq i}} \frac{m_{j} x_{j} x_{n}}{m_{i} D_{i n}^{b}}\right) D_{j k}=c_{i}-\delta_{i k}$

Here $D^{b}{ }_{i j}$ are the binary diffusion coefficients.

Navier-Stokes Equations: The momentum conservation equation is the Navier-Stokes equation:

$\rho \frac{\partial \vec{u}}{\partial t}+\rho \vec{u} \cdot \frac{\partial}{\partial \vec{r}} \vec{u}=$

$-\frac{\partial}{\partial \vec{r}} \hat{P}+\rho \sum_{i=1}^{N_{k}} c_{i} \vec{F}_{i}$

Here $\hat{P}$ is the tensor of pressure:

$\widehat{P}=p \widehat{E}-2 \mu \dot{S}$

$\widehat{E}=\left(\begin{array}{lll}1 & 0 & 0 \\ 0 & 1 & 0 \\ 0 & 0 & 1\end{array}\right)$ is the unit tensor, $p$ is static pressure,

$\dot{S}$ is the rate of strain tensor :

$\dot{S}_{i j}=\frac{1}{2}\left(\frac{\partial u_{i}}{\partial x_{j}}+\frac{\partial u_{j}}{\partial x_{i}}\right)$

$\mu$ is the dynamic viscosity coefficient .This coefficient may be calculated using Wilky formula: 
M.J. Jafari et al. / JAFM, Vol. 4, No. 1, pp. 121-138, 2011.

$$
\mu=\sum_{i=1}^{N} \mu_{i}\left(1+\sum_{\substack{j=1 \\ j \neq i}}^{N k} G_{i j} \frac{x_{i}}{x_{j}}\right)^{-1}
$$

where $\mu_{i}$ is the dynamic viscosity of $i$-th component, and parameters $G_{i j}$ are calculated from the following formula:

$$
G_{i j}=\frac{\left[1+\left(\frac{\mu_{i}}{\mu_{j}}\right)^{\frac{1}{2}}\left(\frac{m_{j}}{m_{i}}\right)^{\frac{1}{4}}\right]^{2}}{2^{\frac{3}{2}}\left[1+\frac{m_{i}}{m_{j}}\right]^{\frac{1}{2}}}
$$

Viscosity of $i$-th component is calculated from the following relationship:

$$
\mu_{i}=266.93 \cdot 10^{-7} \frac{\sqrt{m_{i} T}}{\sigma_{i}^{2} \Omega_{i}^{(2,2) *}\left(T_{i}^{*}\right)} \frac{g}{\mathrm{~cm} \cdot \mathrm{s}}
$$

Collision integrals $\Omega^{(2,2) *}$ in Eq. (11) may be calculated from interpolating the following formula:

$$
\begin{aligned}
& \Omega^{(1,1) *}=1.074 \cdot\left(T^{*}\right)^{-0.1604}, \quad \Omega^{(2,2) *}= \\
& =1.157 \cdot\left(T^{*}\right)^{-0.1472}
\end{aligned}
$$

Energy equations :The equation for conservation of energy has the general form:

$\rho \frac{d h}{d t}+\rho \vec{u} \cdot \frac{d h}{d \vec{r}}=\frac{d p}{d t}-\frac{\partial}{\partial \vec{r}} \cdot \vec{q}+$

$$
+2 \mu \dot{S}^{2}+w_{T}
$$

where: $h=E+\frac{p}{\rho}$ - specific enthalpy of gas mixture, $\vec{q}$ - heat flux, $\dot{S}$ - the rate of strain tensor defined by Eq. (8), $\frac{d}{d t}$ is the full derivative given by: $\frac{d}{d t}=\frac{\partial}{\partial t}+\vec{u} \cdot \frac{\partial}{\partial \vec{r}}$.The second term on the right hand side of equation 13 is the transport energy while the third term represents the heat generation due to viscous friction .The final term of $w_{T}$ represents the energy deposition due to various processes including chemical reactions. The form of this term depends on the form of the applied component enthalpy. For "ordinary "or static thermal enthalpy it becomes: $h=h_{0}+\int_{T_{0}}^{T} c_{p} d T$.

The second term in the right of this equation includes the component of heat formation . Here the suffix" 0 " is used for standard thermodynamic conditions .If thermo-chemical enthalpy is used, then:

$$
h=h_{0}+\int_{T_{0}}^{T} c_{p} d T+\sum_{i=1}^{N_{k}} c_{i} \Delta H_{f}^{i}
$$

on the heat formation of $\Delta H_{f}^{i}$, the chemical source term is equal to zero.

Turbulent flow: The system of gas-dynamic equations may be rewritten in the next tensor form $\left(S_{j}\right.$ is $j$-th Cartesian coordinate, and repeated subscripts denote summation) :

\section{Continuity equation:}

$\frac{\partial \rho}{\partial t}+\frac{\partial}{\partial s_{j}} \rho u_{j}=0$

The component continuity equation can be written as:

$\frac{\partial \rho c_{i}}{\partial t}+\frac{\partial}{\partial s_{j}} \rho u_{j} c_{i}=-\frac{\partial}{\partial s_{j}} J_{i j}+w_{i}$

Momentum conservation equation:

$$
\begin{aligned}
& \frac{\partial}{\partial t}\left(\rho u_{k}\right)+\frac{\partial}{\partial s_{j}}\left(\rho u_{j} u_{k}\right)= \\
& --\frac{\partial p}{\partial s_{k}}+\frac{\partial \tau_{j k}}{\partial s_{j}}+\rho g_{k}
\end{aligned}
$$

Where $\tau_{j k}$ is the viscosity stress tensor.

$$
\begin{aligned}
& \tau_{j k}=2 \mu \dot{S}_{j k}=-\delta_{j k} \frac{2}{3} \frac{\partial u_{j}}{\partial s_{j}}+ \\
& +\mu\left(\frac{\partial u_{j}}{\partial s_{k}}+\frac{\partial u_{k}}{\partial s_{j}}\right)
\end{aligned}
$$

\section{Energy conservation equation:}

$$
\begin{aligned}
& \frac{\partial}{\partial t}(\rho h)+\frac{\partial}{\partial s_{j}}\left(\rho u_{j} h\right)=\frac{\partial p}{\partial t}+ \\
& +u_{j} \frac{\partial p}{\partial s_{j}}+\tau_{j k} \frac{\partial u_{k}}{\partial s_{j}}-\frac{\partial q_{j}}{\partial s_{j}}
\end{aligned}
$$

For turbulent flow the conservation equations are modified to become:

\section{Continuity equation for gas :}

$\frac{\partial \rho}{\partial t}+\frac{\partial}{\partial s_{j}} \rho u_{j}=0$

The continuity equation for $i$-th component can be as the following:

$$
\begin{aligned}
& \frac{\partial \rho c_{i}}{\partial t}+\frac{\partial}{\partial s_{j}} \rho u_{j} c_{i}= \\
& =-\frac{\partial}{\partial s_{j}}\left(J_{i j}+J_{i j}^{T}\right)+w_{i}
\end{aligned}
$$

\section{Momentum conservation equation:}

$\frac{\partial}{\partial t}\left(\rho u_{k}\right)+\frac{\partial}{\partial s_{j}}\left(\rho u_{j} u_{k}\right)=-\frac{\partial p}{\partial s_{k}}+$

$+\frac{\partial\left(\tau_{j k}+\tau_{j k}^{T}\right)}{\partial s_{j}}+\rho g_{k}$

\section{Energy conservation equation:}

$$
\begin{aligned}
& \frac{\partial}{\partial t}(\rho h)+\frac{\partial}{\partial s_{j}}\left(\rho u_{j} h\right)=\frac{\partial p}{\partial t}+u_{j} \frac{\partial p}{\partial s_{j}}+ \\
& +\left(\tau_{j k}+\tau_{j k}^{T}\right) \frac{\partial u_{k}}{\partial s_{j}}-\frac{\partial\left(q_{j}+q_{j}^{T}\right)}{\partial s_{j}}
\end{aligned}
$$


The terms with superscript " $T$ " in Eqs. (20-23) denote turbulent contributions to diffusion flux, stress tensor and heat flux .They are calculated in accordance with model of turbulence.

Turbulence modelling using the $k-\varepsilon$ model :The equation for the turbulence kinetic energy is as follows:

$$
\begin{aligned}
& \frac{\partial}{\partial t}(\rho k)+\frac{\partial}{\partial x_{j}}\left(\rho u_{j} k-\frac{\mu_{e f f}}{\sigma_{k}} \frac{\partial k}{\partial x_{j}}\right)=\mu_{t}\left(P+P_{B}\right) \\
& -\rho \varepsilon-\frac{2}{3}\left(\mu_{t} \frac{\partial u_{i}}{\partial x_{j}}+\rho k\right) \frac{\partial u_{i}}{\partial x_{j}}+P_{N L}
\end{aligned}
$$

Where:

$$
\begin{aligned}
& \mu_{\text {eff }}=\mu+\mu_{t}, P=2 s_{i j} \frac{\partial u_{i}}{\partial x_{j}}, \\
& P_{B}=-\frac{g_{i}}{\sigma_{h, t}} \frac{1}{\rho} \frac{\partial \rho}{\partial x_{i}} .
\end{aligned}
$$

The equation for turbulence dissipation rate is:

$$
\begin{aligned}
& \frac{\partial}{\partial t}(\rho \varepsilon)+\frac{\partial}{\partial x_{j}}\left(\rho u_{j} \varepsilon-\frac{\mu_{e f f}}{\sigma_{\varepsilon}} \frac{\partial \varepsilon}{\partial x_{j}}\right)= \\
& =C_{\varepsilon 1} \frac{\varepsilon}{k}\left[\mu_{t}\left(P+C_{\varepsilon 3} P_{B}\right)-\frac{2}{3}\left(\mu_{t} \frac{\partial u_{i}}{\partial x_{i}}+\rho \varepsilon\right) \frac{\partial u_{i}}{\partial x_{i}}\right]- \\
& \quad-C_{\varepsilon 2} \rho \frac{\varepsilon^{2}}{k}+C_{\varepsilon 4} \rho \varepsilon \frac{\partial u_{i}}{\partial x_{i}}+C_{\varepsilon 1} \frac{\varepsilon}{k} P_{N L}
\end{aligned}
$$

Where: $\sigma_{\varepsilon}, C_{\varepsilon 1}, C_{\varepsilon 2}, C_{\varepsilon 3}, C_{\varepsilon 4}$ are empirical coefficients .

Turbulent viscosity is calculated from $\mu_{t}=f_{\mu} \frac{C_{\mu} \rho k^{2}}{\varepsilon}$ , where $f_{\mu}$ and $C_{\mu}$ may be considered as constant . Parameters $P_{N L}$ is equal to zero for the linear models.

Generalized differential equation: Where the gas under consideration possesses isotropic properties, its equation of motion may be presented in the form of generalized differential equation:

$$
\begin{aligned}
& \frac{\partial \Phi}{\partial t}+\frac{\partial J_{x}}{\partial x}+\frac{\partial J_{y}}{\partial y}+ \\
& +\frac{\partial J_{z}}{\partial z}=S_{\Phi}
\end{aligned}
$$

Where $\mathrm{J}_{\mathrm{x}}, \mathrm{J}_{\mathrm{y}}, \mathrm{J}_{\mathrm{z}}$ are compound convective-diffusion fluxes

$$
\begin{aligned}
& J_{x}=\rho u \Phi-\Gamma_{\Phi} \frac{\partial \Phi}{\partial x} ; \quad J_{i}=\rho v \Phi-\Gamma_{\Phi} \frac{\partial \Phi}{\partial y} ; \\
& J_{z}=\rho w \Phi-\Gamma_{\Phi} \frac{\partial \Phi}{\partial z} ;
\end{aligned}
$$

Where $: u, v, w$ are speed components in Cartesian axes $(x, y, z) ; \Gamma_{\phi}$ - diffusivity; $S_{\phi^{-}}$a source term; $t$-time . The source terms $S_{\phi}$ and diffusivity $\Gamma_{\phi}$ are given in Table 1.
Here $p$ is pressure; $k$-turbulence kinetic energy; $\varepsilon$ turbulence kinetic energy dissipation rate; $\mu_{e f f}$ dynamic effective viscosity factor $\mu_{e f f}=\mu_{t}+\frac{1}{\operatorname{Re}} ; \mu_{t^{-}}$ dynamic turbulent viscosity factor $\mu_{T}=C_{v} f_{v} \frac{k^{2}}{\varepsilon} ; G-$ turbulence generation term; $C_{v}, C_{1}, C_{2}, \sigma_{k}, \sigma_{\diamond}$ empirical constants in $k-\varepsilon$ model.$f_{v} f_{\bar{\varepsilon}^{-}}$correction functions in modified turbulence models $f_{v}=f_{v_{1}} f_{v_{2}}$ , $T$ - temperature, $q$ - internal power sources, $P r_{t}-$ turbulent Prandtl number .

The turbulence kinetic energy generation term $G$ is calculated by the following formula:

$$
G=v_{t}\left\{\begin{array}{l}
2\left[\left(\frac{\partial u}{\partial x}\right)^{2}+\left(\frac{\partial v}{\partial y}\right)^{2}+\left(\frac{\partial w}{\partial z}\right)^{2}\right]+ \\
+\left(\frac{\partial u}{\partial y}+\frac{\partial v}{\partial x}\right)^{2}+\left(\frac{\partial u}{\partial z}+\frac{\partial w}{\partial x}\right)^{2} \\
+\left(\frac{\partial v}{\partial z}+\frac{\partial w}{\partial y}\right)^{2}
\end{array}\right\}
$$

$f_{v} f_{\varepsilon}$ are defined by the following formulas as corrections are inserted into turbulence model. According to the low-Reynolds number model of Jones and Launder (1984) :

$$
\begin{aligned}
& f_{v_{1}}=\exp \left[-2.5 /\left(1+\operatorname{Re}_{t} / 50\right)\right] ; \\
& f_{\varepsilon}=1.0-0.3 \exp \left(-\operatorname{Re}_{t}^{2}\right) ;
\end{aligned}
$$

Where $\operatorname{Re}_{t}=\operatorname{Re} k^{2} / \varepsilon-$ Reynolds turbulent number

The following functions are introduced for Leshtsiner and Rody streamline curvature correction .In 2D case:

$$
\begin{aligned}
& f_{v_{2}}=1 /\left(1+C_{c} R i_{t}\right) ; \\
& R i_{t}=\frac{k^{2}}{\varepsilon^{2}} \sqrt{u^{2}+v^{2}} \frac{1}{R_{c}} \frac{\partial}{\partial R_{c}}\left[R_{c} \sqrt{u^{2}+v^{2}}\right]
\end{aligned}
$$

Where $R i_{t}$ - Richardson turbulent number; $R_{c}$ - local streamline curvature radius; $C_{c}$ - additional empirical constant .

Characteristic liquid density, velocity $\mathrm{U}$ and linear dimension $\mathrm{L}$ are picked to cancel dimensionality .

Finite-Difference Method of Solution: During solving these equations by finite-difference method, significant nonlinearity and existence of a small parameter with a high derivative calls for the occurrence of numerical procedure with a stability problem.To overcome such difficulties in finitedifference approximation, the method of control volumes based on checkerboard grid is used, allowing conservation of finite-difference scheme with any grid size .Besides, the use of checkerboard grid on a meshtype pattern (Fig. 1) allows avoiding of non-physical pulsation in implicit method of pressure determination . The application of a checkerboard mesh, greatly 
simplifies integration procedure of the control volume especially at the edges to calculate the pressure .

Control volume integration of the generalized Eq. (26) results:

$$
\begin{aligned}
& \iint\left[\frac{\partial}{\partial x}\left(u \Phi-\Gamma_{\Phi} \frac{\partial \Phi}{\partial x}\right)+\right. \\
& \left.+\frac{\partial}{\partial y}\left(v \Phi-\Gamma_{\Phi} \frac{\partial \Phi}{\partial y}\right)-S_{\Phi}\right] d x d y=0
\end{aligned}
$$

Using Ostrogradsky-Gauss' law of flux, the following can be obtained:

$$
\begin{aligned}
& \left(\frac{\partial \Phi}{\partial t}\right) v^{\circ} l_{\mathrm{P}}+\left(y_{\eta} u \Phi-\Gamma_{\Phi} \frac{y_{\eta}}{x_{\xi}} \frac{\partial \Phi}{\partial \xi}\right)_{e}- \\
& -\left(y_{\eta} u \Phi-\Gamma_{\Phi} \frac{y_{\eta}}{x_{\xi}} \frac{\partial \Phi}{\partial \xi}\right)_{w}+ \\
& +\left(x_{\xi} v \Phi-\Gamma_{\Phi} \frac{x_{\xi}}{y_{\eta}} \frac{\partial \Phi}{\partial \eta}\right)_{n}- \\
& -\left(x_{\xi} v \Phi-\Gamma_{\Phi} \frac{x_{\xi}}{y_{\eta}} \frac{\partial \Phi}{\partial \eta}\right)_{s}=S_{\Phi_{\mathrm{P}}} \operatorname{vol}_{\mathrm{P}}
\end{aligned}
$$

Let us introduce designations of convection and diffusion factors

$$
\begin{aligned}
& \tilde{N}_{e}=u_{e} y_{\eta e} ; \tilde{N}_{w}=u_{w} y_{\eta w} \\
& \tilde{N}_{n}=v_{n} x_{\xi n} ; \tilde{N}_{s}=v_{s} x_{\xi s} \\
& D_{e}=y_{\eta e} / x_{\xi e} \Gamma_{\Phi e} ; D_{w}=y_{\eta w} / x_{\xi w} \Gamma_{\Phi w} \\
& D_{n}=x_{\xi n} / y_{\eta n} \Gamma_{\Phi n} ; D_{s}=x_{\xi s} / y_{\eta s} \Gamma_{\Phi s}
\end{aligned}
$$

Using the method of derivatives approximation by the control volume and considering that convective members are approximated by the quadratic upwind Leonard scheme we have:

$$
\begin{aligned}
& \frac{\Phi_{\mathrm{P}}^{k+1}-\Phi_{\mathrm{P}}^{k}}{\Delta t}+C_{e} \Phi_{e}^{k+1}-C_{w} \Phi_{w}^{k+1}+ \\
& +C_{n} \Phi_{n}^{k+1}-C_{s} \Phi_{s}^{k+1}=D_{e}\left(\Phi_{E}^{k+1}-\Phi_{P}^{k+1}\right)- \\
& -D_{w}\left(\Phi_{P}^{k+1}-\Phi_{W}^{k+1}\right)+D_{n}\left(\Phi_{N}^{k+1}-\Phi_{P}^{k+1}\right)- \\
& -D_{s}\left(\Phi_{P}^{k+1}-\Phi_{S}^{k+1}\right)+ \\
& +\left(S_{C}+S_{\mathrm{P}} \Phi_{\mathrm{P}}^{k+1}\right) \operatorname{vol}_{\mathrm{P}}
\end{aligned}
$$

The final form of finite-difference equation is:

$$
\begin{aligned}
& \left(a_{\mathrm{P}}+v o l_{\mathrm{P}} / \Delta t\right) \Phi_{\mathrm{P}}^{k+1}= \\
& =\sum a_{n b} \Phi{ }_{n b}^{k+1}+b_{\mathrm{P}}+\Phi_{\mathrm{P}}^{k} \text { vol } l_{\mathrm{P}} / \Delta t
\end{aligned}
$$

Where $: a_{\mathrm{P}}=\sum a_{n b}-S_{\mathrm{P}}$ vol $_{\mathrm{P}}$.

To determine pressure, the SIMPLE algorithm is used, in view of its high stability and speeding up of convergence of the numerical solution .Rewriting the finite-difference equation of momentum and separating the pressure term out.

$$
a_{e} u_{e}=\sum a_{n b} u_{n b}+b_{e}+A_{e}\left(p_{P}-p_{E}\right)
$$

For any given pressure $p^{*}$ and velocity $u^{*}$ distribution equation is:

$$
a_{e} u_{e}^{*}=\sum a_{n b} u_{n b}^{*}+b_{e}+A_{e}\left(p_{P}^{*}-p_{E}^{*}\right)
$$

Having introduced velocity correction : $\delta u=u-u^{*}$

And pressure correction : $\delta p=p-p^{*}$

Then having subtracted the second equation from the first one, we would obtain:

$$
\begin{aligned}
& a_{e} \delta u_{e}=\sum a_{n b} \delta u_{n b}+ \\
& +b_{e}+A_{e}\left(\delta p_{P}-\delta p_{E}\right)
\end{aligned}
$$

Continuity equation for the control volume can be written as:

$-(A u)_{e}+(A u)_{w}-(A v)_{n}+(A v)_{s}=0$

Introducing value of velocity, to the equation, we will obtain an algebraic equation to determine pressure correction.

$$
a_{P} \delta p_{P}=\sum a_{n b} \delta p_{n b}+b_{p}
$$

Where:

$$
\begin{aligned}
& a_{E}=(A d)_{e} ; a_{W}=(A d)_{w} \\
& a_{N}=(A d)_{e} ; a_{S}=(A d)_{s} \\
& a_{P}=\sum a_{n b}
\end{aligned}
$$

This final step in the SIMPLE algorithm procedure will bring the pressure field in conformity with continuity equation .So, we will receive sets of common algebraic equations for calculations of unknown functions in fixed mesh points. These equations are solved by Buleev's method of derogatory matrix factorization (Chia, Chia et al.1982).

Generation of the Grid :To describe the complicated tunnel geometry with a burning vehicle and jet fans in operation, the system of intersecting grids was used .A universal approach was developed for arbitrary curved meshes, which provides description of any complicated geometry of design area.The approach involved a set of grids to estimate fluid flow .Each grid intersects one or several grids of the set.All grids considered are topologically independent .It means that one of them can be a rectangular grid, another one of circle type .

Information interchange between grids is carried out through mutual intersection zones using interpolation dependences, which connect variables in units of different grids .Analysis of calculating procedure for a grid proved that in order to achieve second approximation of convective members of transport 
equations, every mesh must have at least two rows of neighbouring meshes from each side. Exclusion can be made only for meshes located near the body or the external boundary of the design area .This requirement places restrictions on the minimal width of the intersection zone - namely, it must contain not less than four meshes, i.e. two of each grid .

Calculation process for a set of transversal grids is now considered .In general, the consecution of steps is the same as (Guj and Stella 1986).In addition, the following consecution of acts is made for each equation:

1. Coefficients and source members of equations are applied to calculate the values of dependent variables.

2. Increments in bound meshes are calculated for every grid, through iteration. The procedure is repeated until some consistent convergence criterion in all areas is arrived at.

3. New values of variables are determined before proceeding to the next equation .

It should be noted that such procedure of equation solving allows parallelization by areas, if increments in bound meshes are not calculated but equated with zero . This is acceptable, although it reduces convergence velocity.

Implementation of Test Calculation :Accuracy was tested by implementing a number of special calculations.Results of theoretical solutions were compared with results of experimental researches. Results from an experiment, carried out in All-Russian Research Institute of Fire Prevention (VNIIPO) were used as experimental benchmark data (Hackman, Raithby et al. 1984) .

Stability and convergence tests were carried out with the present algorithm .For this purpose, the calculation of a burning truck was implemented for two types of grids. The first grid was two times wider than the second one.The duration of modelling was 300 seconds.The profile of the variation of average temperature across the tunnel cross section along the whole tunnel length was compared every 30 seconds . Differences in temperature at any section were less than $0.001{ }^{\circ} \mathrm{C}$ for the two grid sizes .Long duration modelling (longer than 1000 seconds) showed no unstable calculations. So it was concluded that the developed algorithm has a good convergence and stability .All tests showed that the proposed algorithm meets all accuracy, convergence and stability requirements with reasonable confidence for the grid sizes considered in the modelling. Figure 3 illustrates the results of implemented tests. This figure shows that the predicted and implemented test results (for 1000 seconds after the fire incident) agree with each other

\section{Results}

Numerical modelling of a conventional $25 \mathrm{MW}$ fire was carried out for two values of air velocity along the tunnel (e.g. $V=3.87 \mathrm{~m} / \mathrm{s}$ and $11.71 \mathrm{~m} / \mathrm{s}$ ) . Such fire is associated with burning of a heavy truck loaded with conventional goods.Air velocities represent two ventilation capacities required for the east and the west tunnel, respectively .The gradient of the east tunnel is $1.63 \%$ while the gradient of the west tunnel is $+1.63 \%$. The gradients mainly affect the ventilation capacities of the two tunnels.In the text that follows, numerical results are presented separately for each longitudinal air velocity along the tunnel.

Fire in the east tunnel. The first fire alternative was calculated for the east tunnel with air velocity of $3.87 \mathrm{~m} / \mathrm{s}$ under normal ventilating mode.In the following part, temperature fields are explained first. The smoke distribution along the tunnel section is presented next.

Temperature Fields :With a heavy duty vehicle fire in the east tunnel and a longitudinal air velocity of 3.87 $\mathrm{m} / \mathrm{s}$, the temperature variation along the tunnel will be as in Figs. 4 and 5. The air flow direction is from left to right, and the figures depict the temperature fields in vehicle's symmetry plane at different moments of time .

The results reveal that at the end of first ventilation mode (e.g. $t=180 \mathrm{sec}$ ), the temperature $T$ at the right boundary of the tunnel section reaches $200^{\circ} \mathrm{C}$. Figure 4 shows that temperature will rise to $150^{\circ} \mathrm{C}$ at the tunnel floor after 120 seconds. The air velocity of $3.87 \mathrm{~m} / \mathrm{s}$ along the tunnel prevents back layering of the hot gases during the first $180 \mathrm{sec}$ (Fig. 4).

The results also reveal that the air temperature will reach $400{ }^{\circ} \mathrm{C}$ in large zones at the down stream of the fire location $780 \mathrm{sec}$ after the fire starts (Fig. 4) . The tunnel structure, fans and other electro-mechanical parts located in this area will be exposed to this temperature causing them to fall off in a short time as it happened in the Channel Tunnel fire of 1995 .

Since the air velocity along the tunnel decreases in the evacuation mode thus, the hot gases spread at the upstream of the fire location .According to Fig. 5, the air temperature at the upstream of the fire location reaches up to $200{ }^{\circ} \mathrm{C}$ at the end of evacuation mode or $780 \mathrm{sec}$ after fire starts. This condition is not acceptable from safety point of view .It shows that all vehicles and people in this area must also be evacuated fast. The fire fighters and rescue teams will only be able to reach from upstream of the fire which will be blocked by incoming traffic .

In the smoke extraction mode, hot gases penetrate the left portion of the tunnel in large quantities, and the temperature of large area near burning vehicle reaches the value of $T=900^{\circ} \mathrm{C}$. Numerical results show that the air velocity during the smoke extraction is not high enough to extract all hot gasses .

Smoke Distribution :Smoke distribution is given on Figs. 6 and 7. Smoke concentration will reach between 10 and $15 \%$ at tunnel floor $180 \mathrm{sec}$ after the beginning of the fire.

The results show that $780 \mathrm{sec}$ after the beginning of the fire, the smoke concentration will reach higher than $30 \%$ and $15 \%$ respectively at the down stream and upstream of the fire location. As the ventilation is switched to evacuation mode (e.g. $180 \mathrm{sec}$ after fire started), smoke starts back layering and to spread at the upstream of the fire location where there people and vehicles could be entrapped. Smoke fills up the left part 
of tunnel section gradually. This result shows that the air velocity along the tunnel is not high enough to prevent the smoke from back layering in evacuation mode.

The numerical calculations show that $1200 \mathrm{sec}$ after the beginning of the fire, the smoke concentration at the upstream and down stream of the fire location will reach up to 40 and $95 \%$ respectively (Fig. 7).

Fires in the west tunnel The second alternative for conventional fire was calculated with air velocity of $11.71 \mathrm{~m} / \mathrm{s}$ under normal ventilating mode. This ventilation capacity corresponds to the west tunnel with an up going gradient of $+1.63 \%$.In the following, temperature fields and smoke distribution along the tunnel section are presented separately.

\subsubsection{Temperature Fields}

The results show that $180 \mathrm{sec}$ after the beginning of the fire, the temperature will be around 20 to $50^{\circ} \mathrm{C}$ at the vicinity of the fire but there will be a patch of a high temperature zone at 150 meters from the fire location with an average temperature of $175^{\circ} \mathrm{C}$ (Fig. 8).

Figure 8 shows that, at the end of second ventilation mode (e.g. $\mathrm{t}=780 \mathrm{sec}$ ) the temperature will go as high as $500^{\circ} \mathrm{C}$ at both sides of the fire location .

At the end of smoke extraction mode (e.g. $t=1200 \mathrm{sec}$ ), temperature at tunnel wall may go up to $900^{\circ} \mathrm{C}$ in 150 metres from the fire location

Smoke Concentration: Figures 10 and 11 depict the smoke concentration of the fire in west tunnel. The results show that at the end of first ventilation mode (e.g. $t=180 \mathrm{sec}$ ), the smoke concentration will go as high as $15 \%$ at 150 meters from the fire location but it will be much lower at the vicinity of the fire (Fig. 10) .

Figure 11 shows that at the end of the second ventilation mode (e.g. $\mathrm{t}=780 \mathrm{sec}$ ), the smoke concentration will go up to $45 \%$ (Fig. 11). According to the results obtained form this study, the smoke concentration will go up to $95 \%$ at the tunnel section, $1200 \mathrm{sec}$ after the beginning of the fire (Fig. 11).

\section{DISCUSSION}

For design purposes, it is necessary to choose typical fire characteristics corresponding to the traffic which uses a particular tunnel .In its report for Brussels World Road Congress in 1987, the Committee on Road Tunnels proposed the typical fires corresponding to the bus and truck fires to be $20 \mathrm{MW}$ in power .According to Bendelius 1996, a $20 \mathrm{MW}$ fire is approximately equivalent to a bus or truck fire, therefore, the fire simulated in this study can be considered as a typical fire corresponding to heavy duty vehicle fire (Bendelius 1996) .

Longitudinal air velocity measured in real tunnel fire tests shows that air velocity of 2.5 to $2.9 \mathrm{~m} / \mathrm{s}$ controls the back layering of smoke in the Memorial Tunnel over the range of fire size tested (10 to $100 \mathrm{MW}$ ). Simulation results in present study show that back layering starts only when the air velocity is less than 3 $\mathrm{m} / \mathrm{s}$ in the evacuating mode of ventilation which well agrees with results obtained from real tunnel fires.
It is possible to make a rough estimate of the tunnel conditions that must be maintained for evacuation and fire fighting operations .Evacuation time can be several minutes, depending on the distance to exits and walking speed .According to Lacroix and Arditi (1996), while normal walking speed to emergency exits is $1.5 \mathrm{~m} / \mathrm{s}$, it may be reduced to about $1 \mathrm{~m} / \mathrm{s}$ owing to the presence of smoke .For such a walking speed the evacuation time can be between 250 and 600 seconds. The evacuation period was considered to be 600 seconds in present study.

To make evacuation possible, the radiation level must be under the limit which causes severe pain on bare skin for exposure of several minutes. The threshold value is about 2 to $2.5 \mathrm{~kW} / \mathrm{m}^{2}$. Fire fighters can normally withstand a higher radiation of $5 \mathrm{~kW} / \mathrm{m}^{2}$. Their operation time is not longer than 30 minutes even when wearing a breathing apparatus.Near the fire, the radiation is created by the fire itself as well as the hot smoke .Further away it is only the smoke temperature which creates a dangerous condition. Some authors believe that a temperature of $160^{\circ} \mathrm{C}$ in a smoke layer at the tunnel ceiling gives a radiation level of about $2 \mathrm{~kW} / \mathrm{m}^{2}$ at the user's level (Lacroix and Arditi 1996) . According to the same authors, at $270{ }^{\circ} \mathrm{C}$ it gives about $5 \mathrm{~kW} / \mathrm{m}^{2}$.Considering these limits, the numerical results in present study show that, with a truck or bus fire in tunnel, it is possible to carry out the fire fighting operation within 13 minutes from the beginning of the fire by firemen using breathing apparatus (Figs. 5 \& 9) . The time taken is much less than the 30 minutes recommended for the fire fighting operation.

According to some authors the air temperature of not more than $80^{\circ} \mathrm{C}$ can be tolerated for 15 minutes . Considering this, with a truck or bus fire in the Taloon tunnel, every one must leave the fire point in 3 minutes (e.g. before ventilation system is changed to evacuation mode).

There is no reliable published method to calculate the concentration of the toxic or irritant gases released in a vehicle fire, and tolerable concentrations are not prescribed by PIARC .It is expected that in many tunnel fires, ensuring the minimum visibility will maintain the dangerous gases concentrations under the tolerable limit for evacuation.

According to PIARC recommendations, a visibility distance of $7 \mathrm{~m}$ is required to walk smoothly in a smoky atmosphere .To read the signs the distance must be 15 $\mathrm{m}$.Thus, a minimum visibility distance of 7 to $15 \mathrm{~m}$ must be aimed at for evacuation and fire fighting operations. When linking the smoke concentration with the evaluation of the visibility, it can be concluded, that even very low smoke concentrations (around 5 (\%result in a total lack of visibility (range of sight $<1 \mathrm{~m}$ ). This fact has been fully confirmed by persons entering the smoke area of the test tunnels (Feizlmayr 1976). Figures $6 \& 10$ show that considering this value of concentration, the tunnel would be safe only at the upstream of the fire location for 5 minutes after the fire breaks.

Falling off of the concrete must not prevent people from escaping or injure firemen .According to PIARC, concrete may start to fall off at a surface temperature of 
$150-200^{\circ} \mathrm{C}$, after 15 minuets . For tunnels with no lining or with natural stone masonry, this limit can be lower . Numerical results from the present study reveal that the wall surface temperature at down stream of the fire location will rise up to this level 30 seconds after the fire begins. The wall surface temperature at the upstream of the fire point will rise up to this level 3 minutes after the beginning of the fire .

Considering the tunnel length and the distance between jet fans installed in the Taloon tunnel, a sufficient number of fans and other fire protection measures will withstand the fire long enough to control smoke during escape and fire fighting. Previous studies of Memorial Tunnel fire tests show that the fans and other equipment close to the fire point can be seriously damaged from heat.Thus the use of additional jet fans is recommended during smoke control during escape and fire fighting operations .

People who are in a tunnel during a fire are, generally, not so much in danger due to the high temperatures as due to the toxic gases and dense smoke, therefore, it is important to know how the smoke spreads within the tunnel .

The most important results coming from research and fire tests is that the hot smoke under certain conditions (e.g. low longitudinal air speed, slope and etc.) fill the upper part of the tunnel, While the lower part of the tunnel cross section may be kept free of smoke for a considerable time and over a long distance from the fire. This well agrees with present numerical results.

\section{ACKNOWLEDGEMENT}

The authors acknowledge with thanks the financial support provided by Azad Rahe Tehran - Shomal and Laniz companies and the contribution of the university of Shahid Beheshti (MC) and Industrial Aerodynamics Dept of Aerospace Research Centre of Russia for this study.

\section{REFERENCES}

Bendelius, A.G. (1996). The Memorial Tunnel fire ventilation test program. Proc. Protection from Fire in Rail and Road Tunnels, Rome, Italy.

Bendelius, A.G. (October, 1997). The Memorial Tunnel fire ventilation test program-past, present and future. Proc 9th International Symposium on the Aerodynamics and Ventilation of Vehicle Tunnels, Aosta Valley, Italy, BHRA Group Limited.

Bettis, R.J., S.F. Jagger, et al. (1994). The use of physical and mathematical modeling to asses the hazards of tunnel fires. Proc 8th International Symposium on the Aerodynamics and Ventilation of Vehicle Tunnels, Liverpool, UK.

Biollay, H. and P. Chasse (1994). Validating and optimizing $2 \mathrm{D}$ and $3 \mathrm{D}$ computer simulations for the Ofenegg tunnel fire tests. Proc 8th International Symposium on the Aerodynamics and Ventilation of Vehicle Tunnels, Liverpool, UK.
Chia, U., K.N. Chia, et al. (1982). High-Resolutions for incompressible flow using Navier-Stokes equations and a multigrid method. $J$.Comput.Phys 48(N2), 387-411.

Chow, W.K. and W.M. Leung (1988). Application of field model to tunnel fire services design. Proc 6th International Symposium on the Aerodynamics and Ventilation of Vehicle Tunnels, Durham, UK, BHRA the fluid engineering.

Feizlmayr, A.H. (1976). Research in Austria on tunnel fire. Proc 2nd International Symposium on the Aerodynamics and Ventilation of Vehicle Tunnels, Cambridge, UK.

Guj, G. and F. Stella (1986). A numerical solutions of high Re numbers recirculating flows in vorticityvelocity coordinate system. Atti 8 Congress Nat . Assoc.Ital .Mech.Theor.and Appl .(AIMEYA 86), Torino, Italy.

Hackman, Z.P., G.D. Raithby, et al. (1984). Numerical predictions of flow over backward-facing step. Int. J. Numer. Fluids 4(N8), 711-724.

Jafari, M.J. (1997). A Predictive Support Tool for Road Tunnel Ventilation Control. Civil Engineering Dept. Dundee, UK, University of Dundee, PhD 220.

Kawabata, N., H. Ohashi, et al. (1991). Numerical simulation of fire fume propagation along the ceiling of a down-grade tunnel. Proc 7th International Symposium on the Aerodynamics and Ventilation of Vehicle Tunnels, Brighten, UK, BHRA the fluid engineering center.

Kumar, S. and G. Cox (1985). Mathematical modeling of fires in road tunnels. Proc 5th International Symposium on the Aerodynamics and Ventilation of Vehicle Tunnels, Lille, France, BHRA the fluid engineering center.

Kumar, S. and G. Cox (1988). Radiant heat and surface roughness effects in the numerical modeling of tunnel fires. Proc 6th International Symposium on the Aerodynamics and Ventilation of Vehicle Tunnels, Durham, UK, BHRA the fluid engineering.

Kuriokaa, H., Y. Oka, et al. (2003). Fire properties in near field of square fire source with longitudinal ventilation in tunnels. Fire Safety Journal 38(4), 319-340.

Lacroix, D. (1994). PIARC activities on fire and smoke control in road tunnels. Proc 8th International Symposium on the Aerodynamics and Ventilation of Vehicle Tunnels, Liverpool, UK.

Lacroix, D. (1996). Research Advancement in France on Road Tunnel Safety. Proc, Protection from Fire in Rail and Road Tunnels, Rome, Italy. 
M.J. Jafari et al. / JAFM, Vol. 4, No. 1, pp. 121-138, 2011.

Lacroix, D. and R. Arditi (1996). PIARC activities and recommendations on fire and smoke control in road tunnels. Proc, Protection from Fire in Rail and Road Tunnels, Rome, Italy, 49-60.

Lonnermark, A. and H. Ingason (2005). Gas temperatures in heavy goods vehicle fires in tunnels. Fire Safety Journal 40(6), 506-527.

Malalasekera, W.M.G. and F. Lockwood (1991). Computer Simulation of the King Cross fire effect of radiative heat-transfer on fire spread. Journal of mechanical engineering sciences Proceedings of the institution of mechanical engineers part C 205(3), 201-208.
PIARC (1999).Fire and smoke control in road tunnels. P.I.R. Congresses, PIARC.

Rhodes, N. (1994). Review of tunnel fire and smoke simulations. Proc 8th International Symposium on the Aerodynamics and Ventilation of Vehicle Tunnels, Liverpool, UK.

Rhodes, N. (1996). Computer aided analysis for fire safety in subways. Proc, Protection from Fire in Rail and Road Tunnels, Rome, Italy.

Simcox, S., N.S. Wikes, et al. (1992). Computer simulation of the flows of hot gases from the fire at king's Cross Underground station. Fire Safety Journal 18(1), 49-73.

Table 1 Source terms $S_{\Phi}$ and diffusivity $\Gamma_{\Phi}$

\begin{tabular}{|l|l|l|}
\hline$\Phi$ & \multicolumn{1}{|c|}{$\Gamma_{\Phi}$} & $S_{\Phi}$ \\
\hline 1 & 0 & 0 \\
\hline$U$ & $\mu_{\text {eff }}$ & $-\frac{\partial p}{\partial x}+\frac{\partial}{\partial x}\left(\mu_{\text {eff }} \frac{\partial u}{\partial x}\right)+\frac{\partial}{\partial y}\left(\mu_{\text {eff }} \frac{\partial v}{\partial x}\right)+\frac{\partial}{\partial z}\left(\mu_{\text {eff }} \frac{\partial w}{\partial x}\right)$ \\
\hline$V$ & $\mu_{\text {eff }}$ & $-\frac{\partial p}{\partial y}+\frac{\partial}{\partial x}\left(\mu_{\text {eff }} \frac{\partial u}{\partial y}\right)+\frac{\partial}{\partial y}\left(\mu_{\text {eff }} \frac{\partial v}{\partial y}\right)+\frac{\partial}{\partial z}\left(\mu_{\text {eff }} \frac{\partial w}{\partial y}\right)$ \\
\hline$W$ & $\mu_{\text {eff }}$ & $-\frac{\partial p}{\partial z}+\frac{\partial}{\partial x}\left(\mu_{\text {eff }} \frac{\partial u}{\partial z}\right)+\frac{\partial}{\partial y}\left(\mu_{\text {eff }} \frac{\partial v}{\partial z}\right)+\frac{\partial}{\partial z}\left(\mu_{\text {eff }} \frac{\partial w}{\partial z}\right)$ \\
\hline$K$ & $\frac{\mu_{t}}{\sigma_{k}}+\frac{1}{\operatorname{Re}}$ & $G-\varepsilon$ \\
\hline$\varepsilon$ & $\frac{\mu_{t}}{\sigma \varepsilon}+\frac{1}{\operatorname{Re}}$ & $\frac{\varepsilon}{k}\left(C_{1} G-C_{2} f_{\varepsilon} \varepsilon\right)$ \\
\hline$T$ & $\frac{\mu_{t}}{\operatorname{Pr}_{t}}+\frac{1}{\operatorname{Re}}$ & $P q$ \\
\hline
\end{tabular}

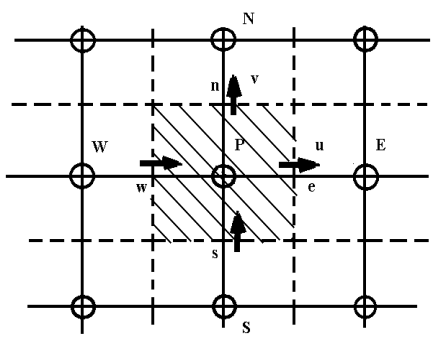

Fig. 1. Sub - Image of heckerboard rid

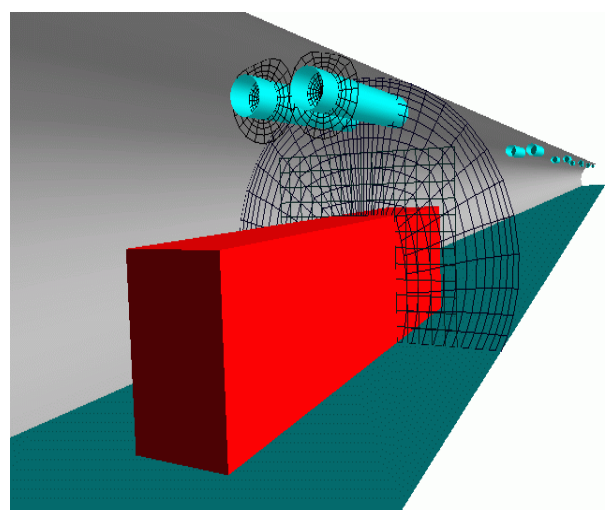

Fig. 2. The grid patches for twin fans 


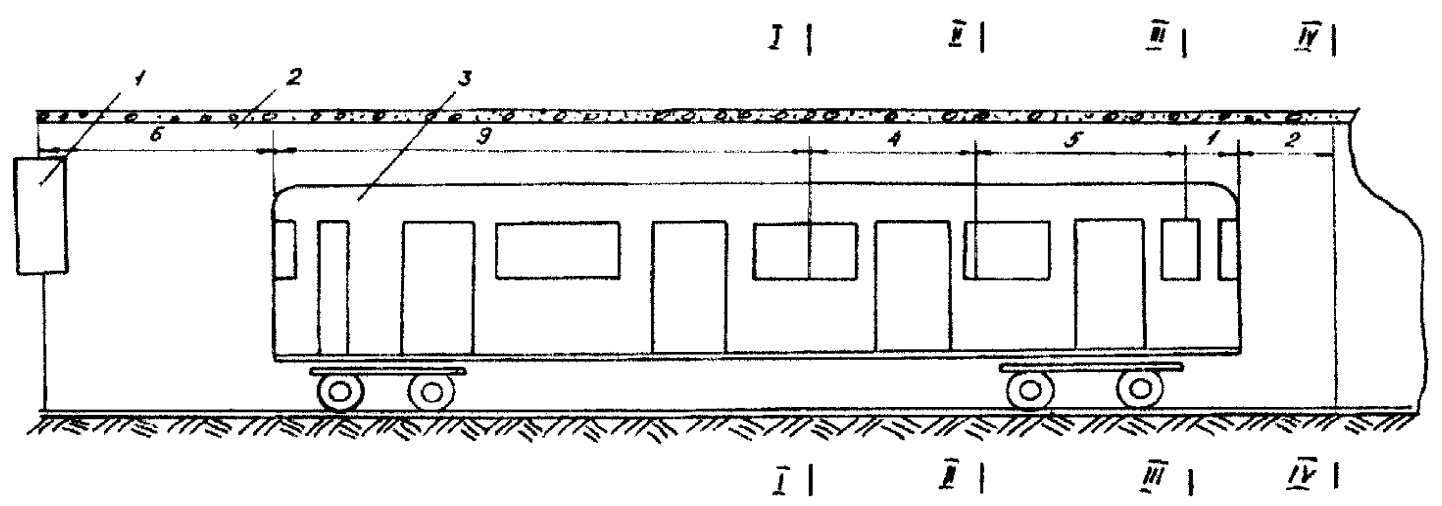

The scheme of railcar allocation in track tunnel model $: 1$ - ventilating installation;

2 - tunnel model; 3 - prototype railcar .I - IV :tunnel sections with thermocouple installed
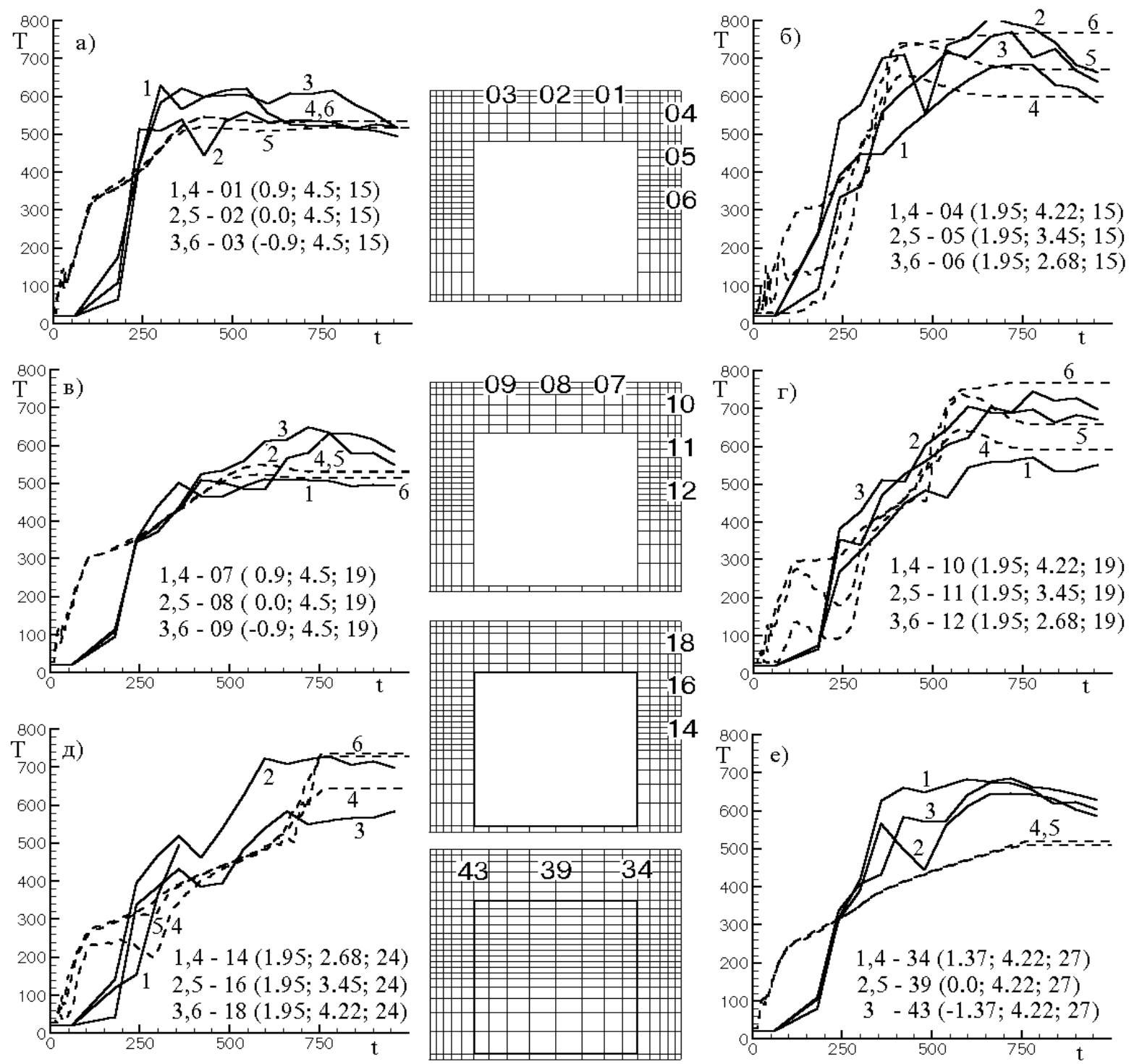

Fig .3. Experimental (continuous curves 1-3) and predicted (dotted curves 4-6) temperature (in ${ }^{\circ} \mathrm{C}$ ) versus time (in seconds) at different points of tunnel sections: I (a,b), II( c,d), III (e), IV (f) .Points are numbered, and their location is determined in meters and is given in brackets: longitudinal, measured from middle of tunnel section, vertical coordinate and distance between sections of tunnel front. 

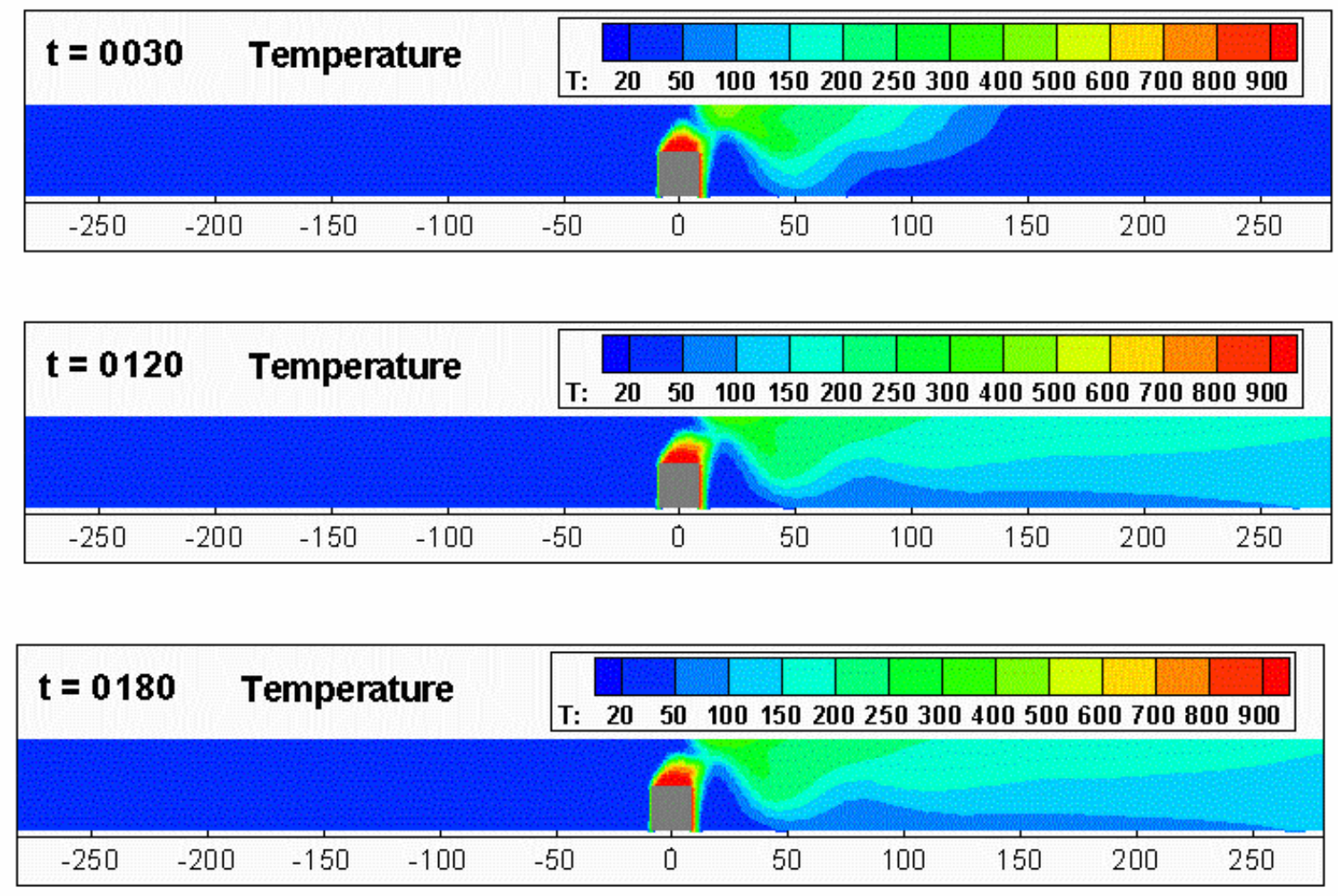

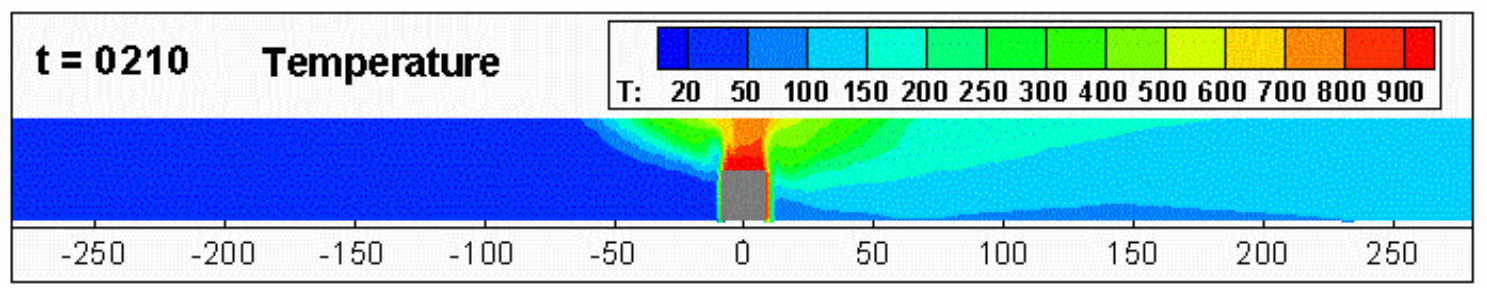
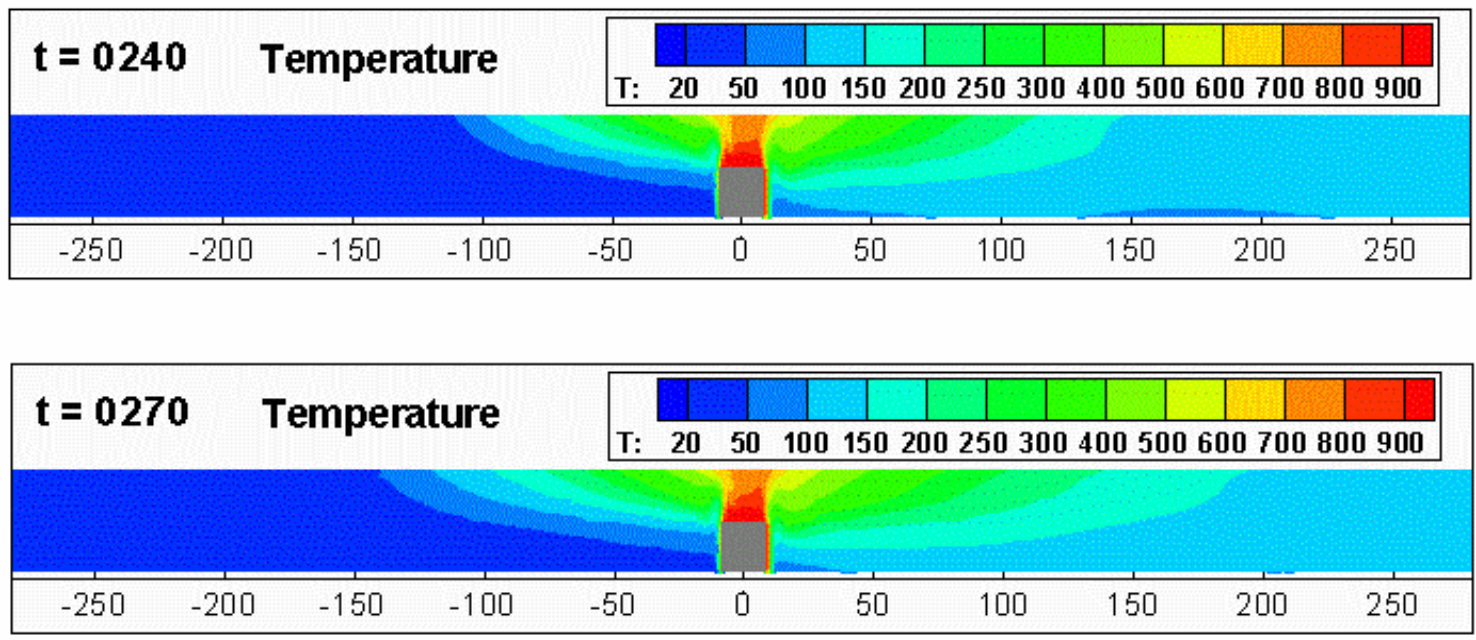

Fig. 4. Temperature fields from heavy truck fire in east tube $(V=3.87 \mathrm{~m} / \mathrm{s})$. 

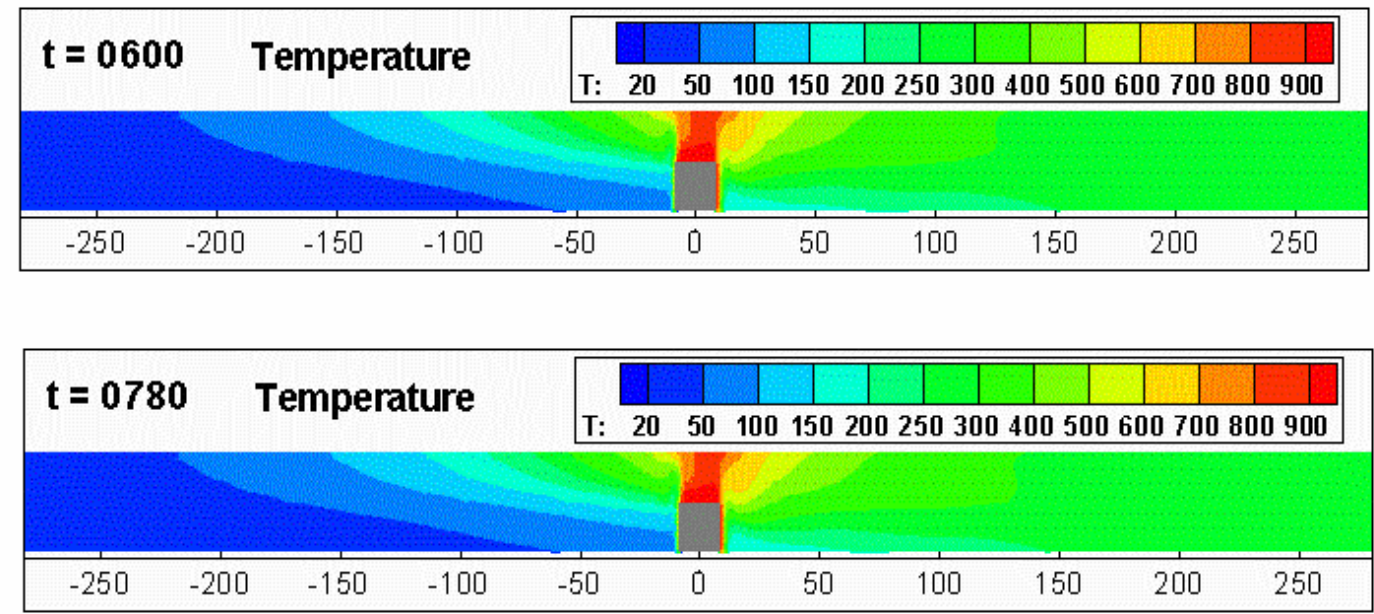

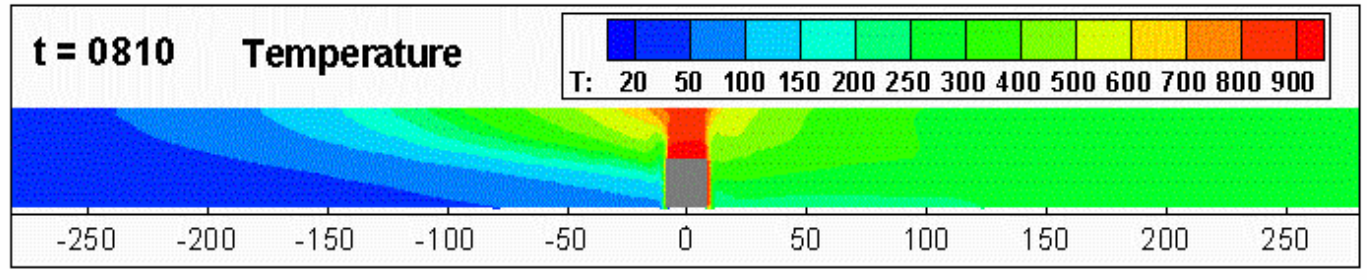

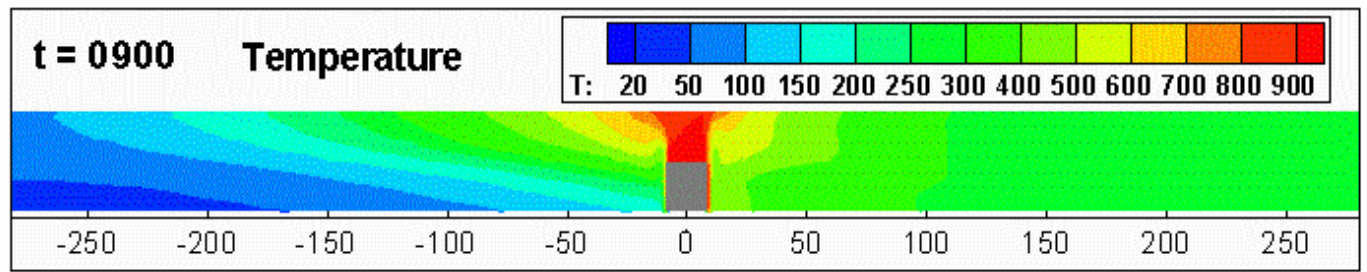

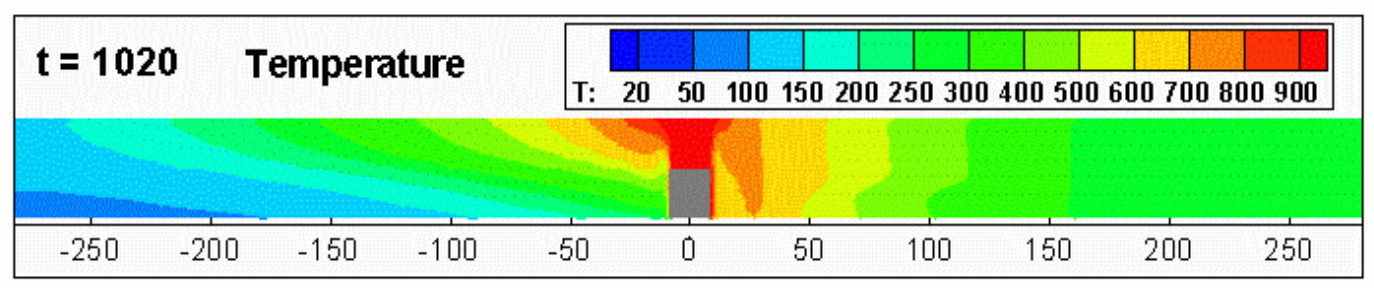

\begin{tabular}{|c|c|c|c|c|c|c|c|c|c|c|}
\hline \multicolumn{2}{|c|}{$t=1200$} & \multicolumn{2}{|c|}{ Temperature } & \multicolumn{7}{|c|}{ T: $\quad 20 \quad 50 \quad 100150200250300400500600700800900$} \\
\hline-250 & -200 & -150 & -100 & -50 & 0 & 50 & 100 & 150 & 200 & 250 \\
\hline
\end{tabular}

Fig. 5. Temperature fields from heavy truck fire in east tube $(\mathrm{V}=3.87 \mathrm{~m} / \mathrm{s})$. 

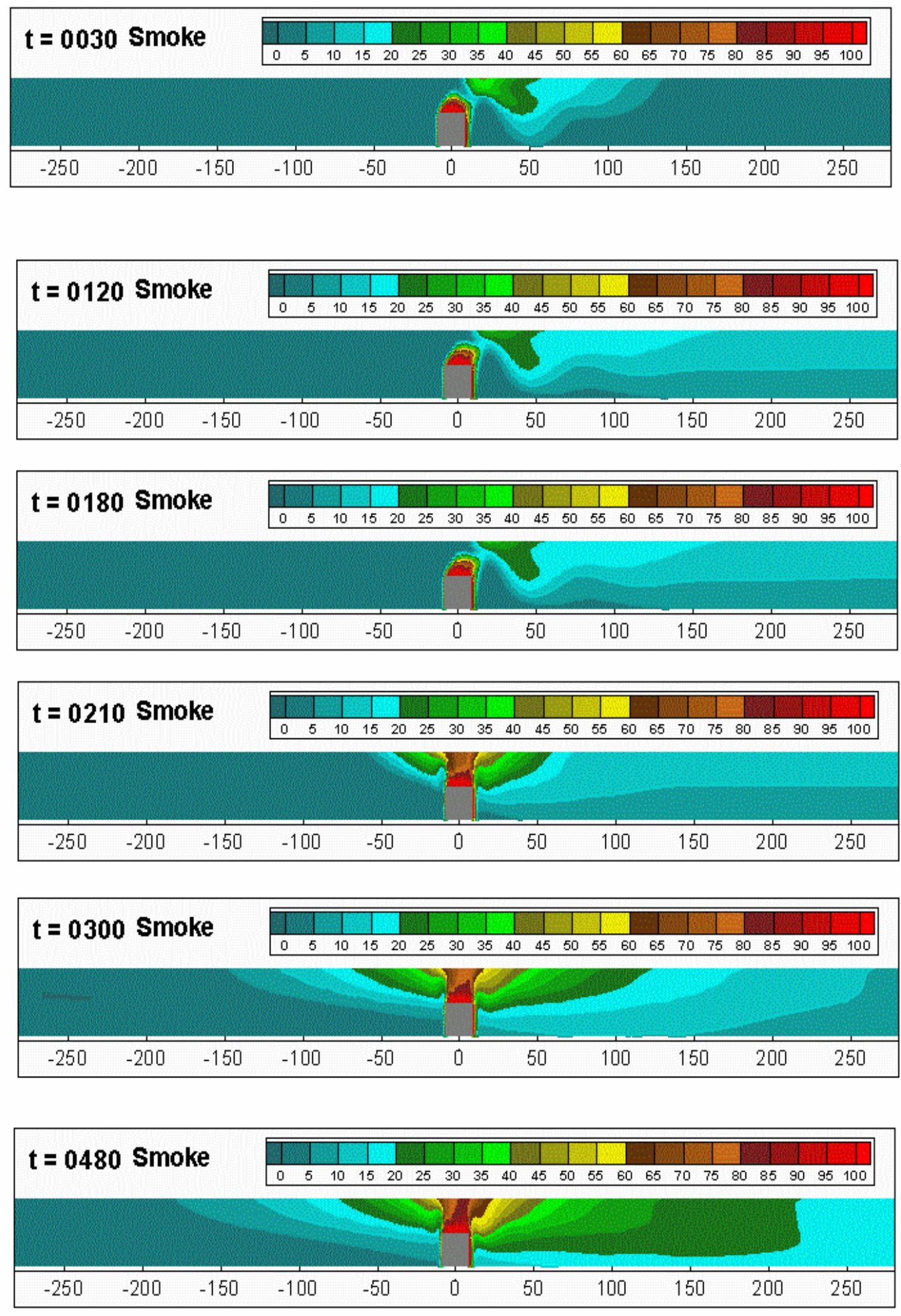

Fig. 6. Smoke concentration in tunnel air from heavy truck fire (east tube, $\mathrm{V}=3.87 \mathrm{~m} / \mathrm{s}$ ). 

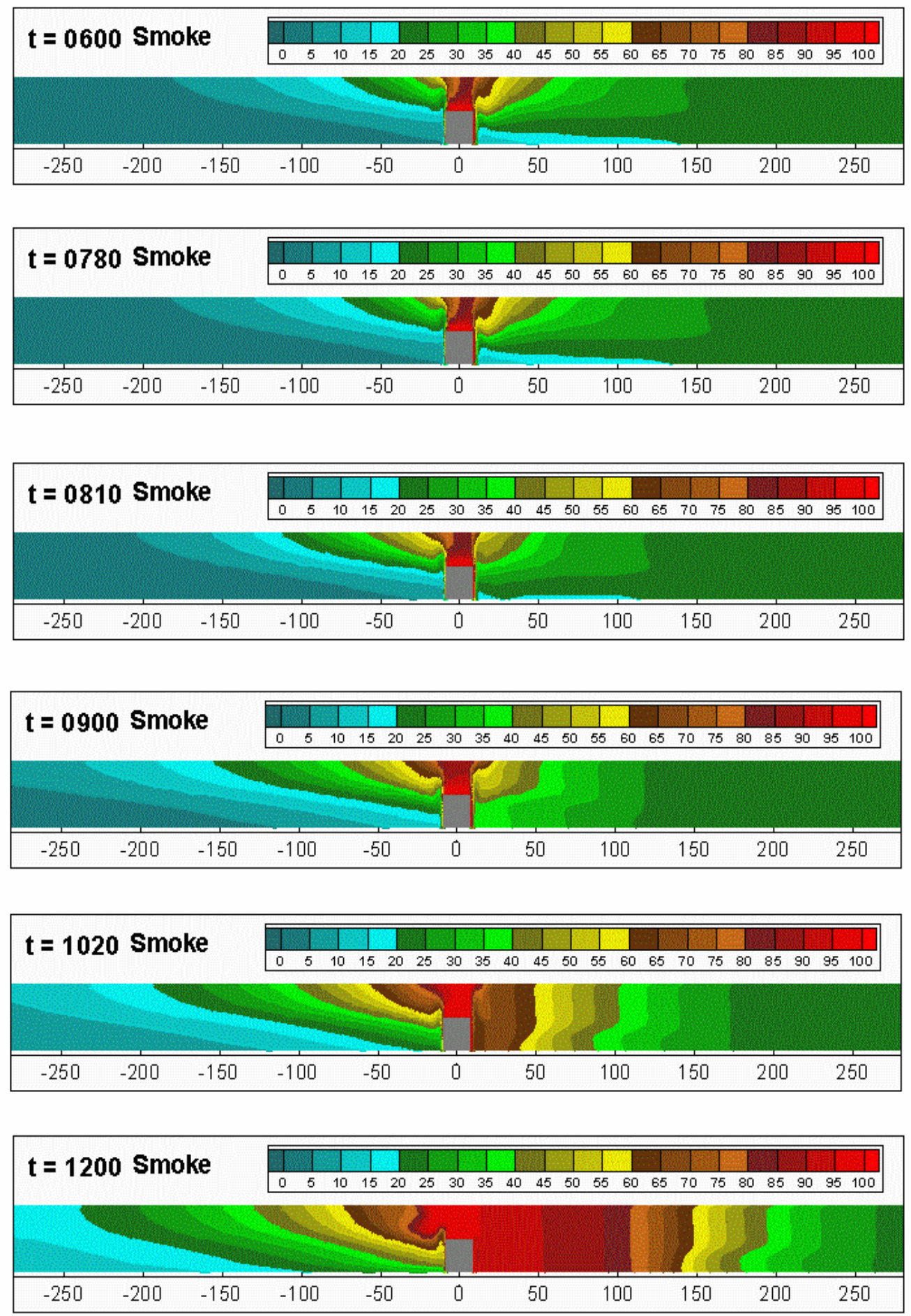

Fig. 7. Smoke concentration in tunnel air from heavy truck fire (east tube, $V=3.87 \mathrm{~m} / \mathrm{s}$ ). 


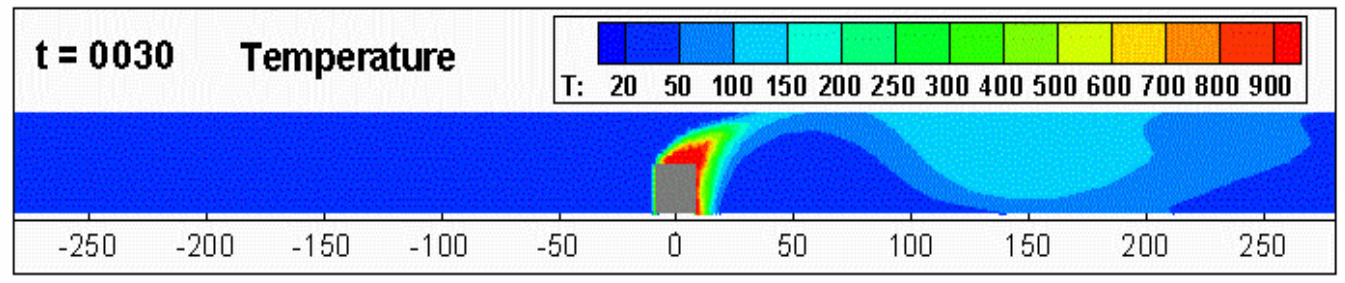

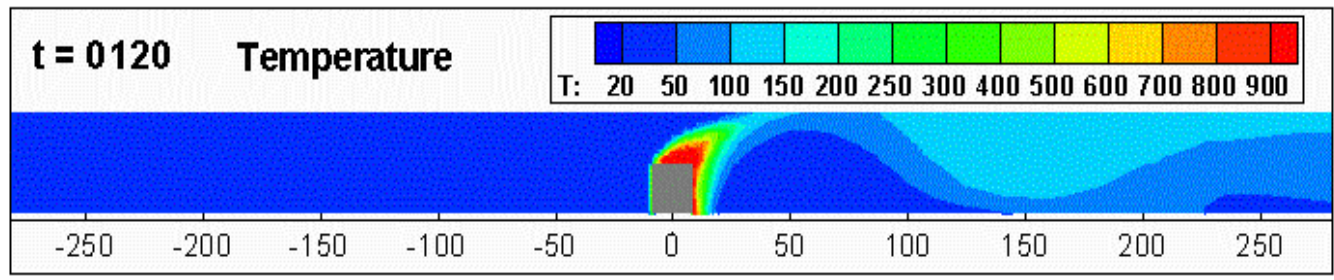

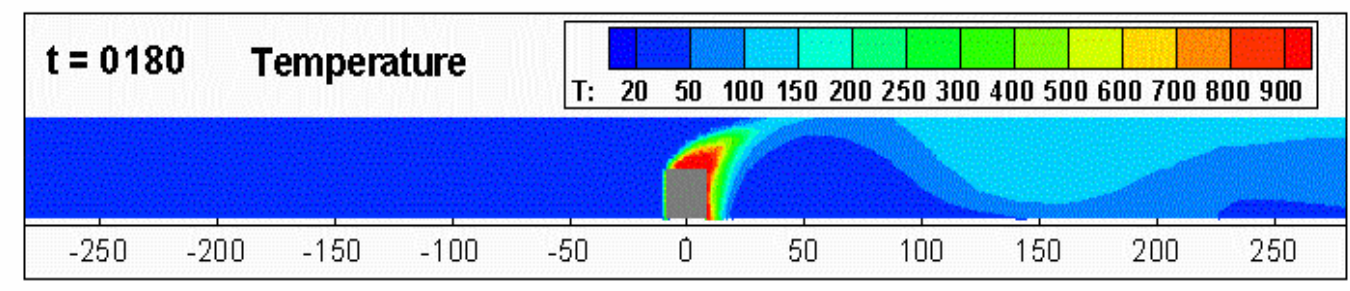
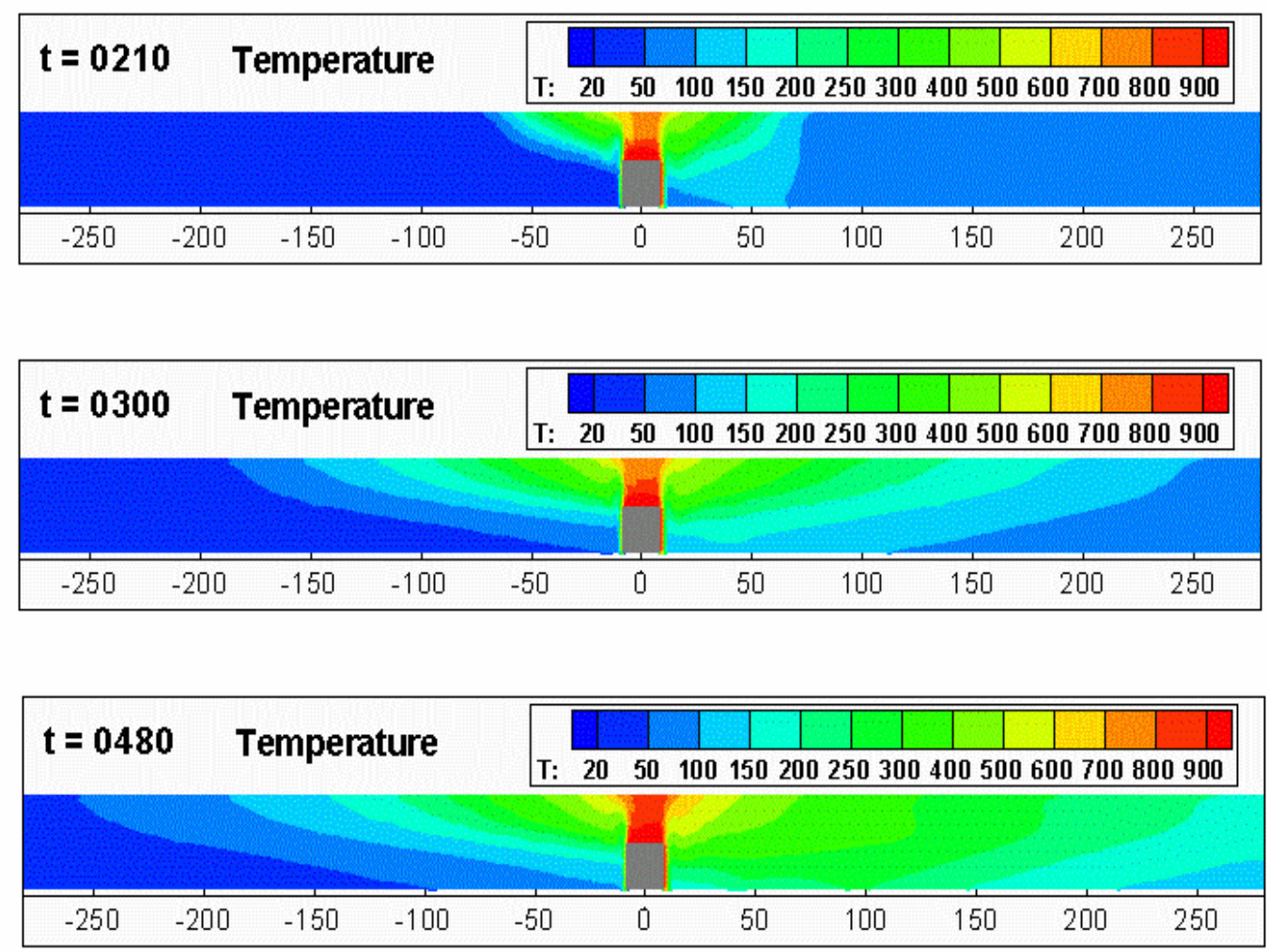

Fig. 8. Temperature fields from heavy truck fire in west tube $(\mathrm{V}=11.71 \mathrm{~m} / \mathrm{s})$. 

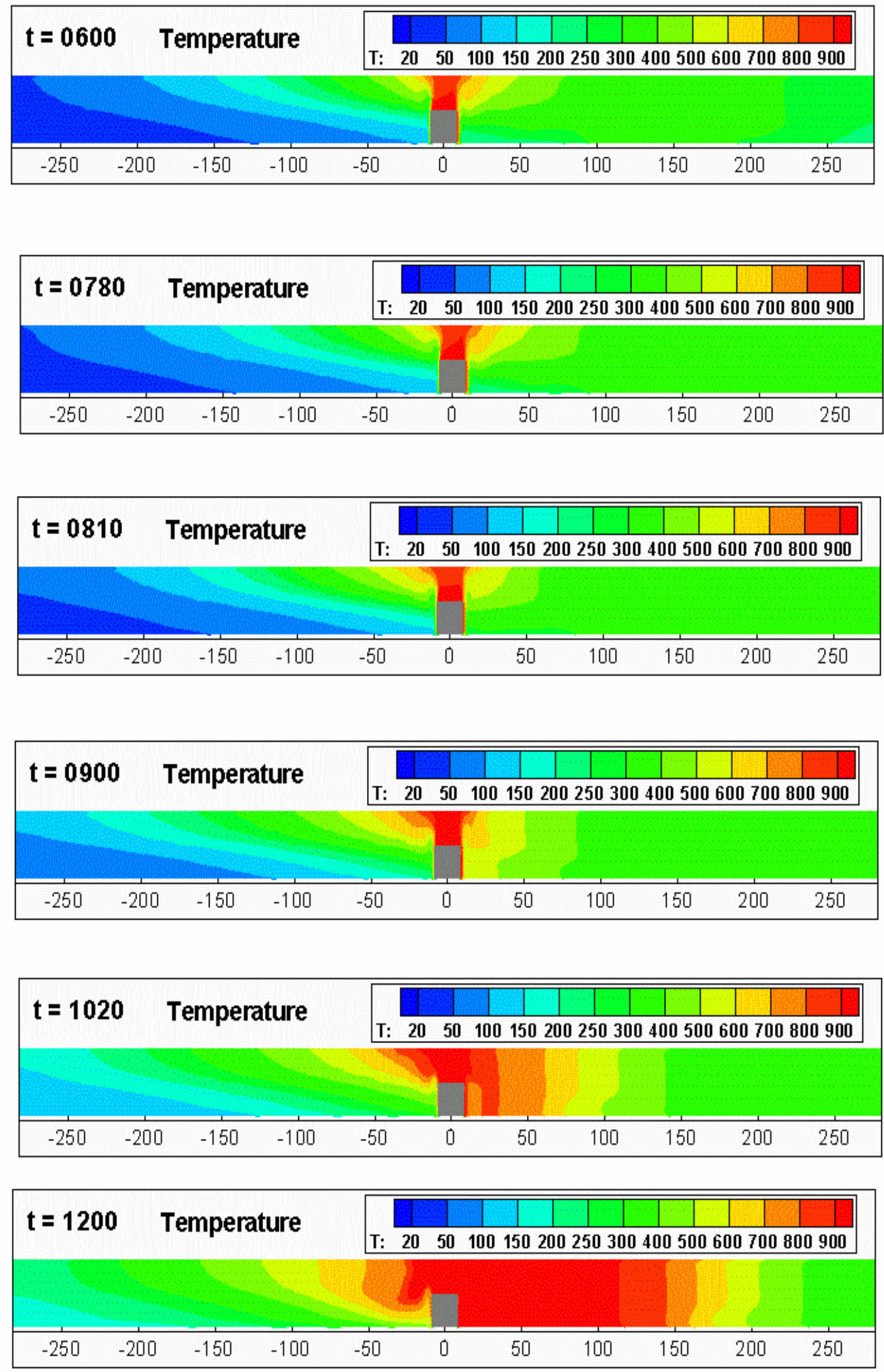

Fig. 9. Temperature fields from heavy truck fire in west tube $(\mathrm{V}=11.71 \mathrm{~m} / \mathrm{s})$. 

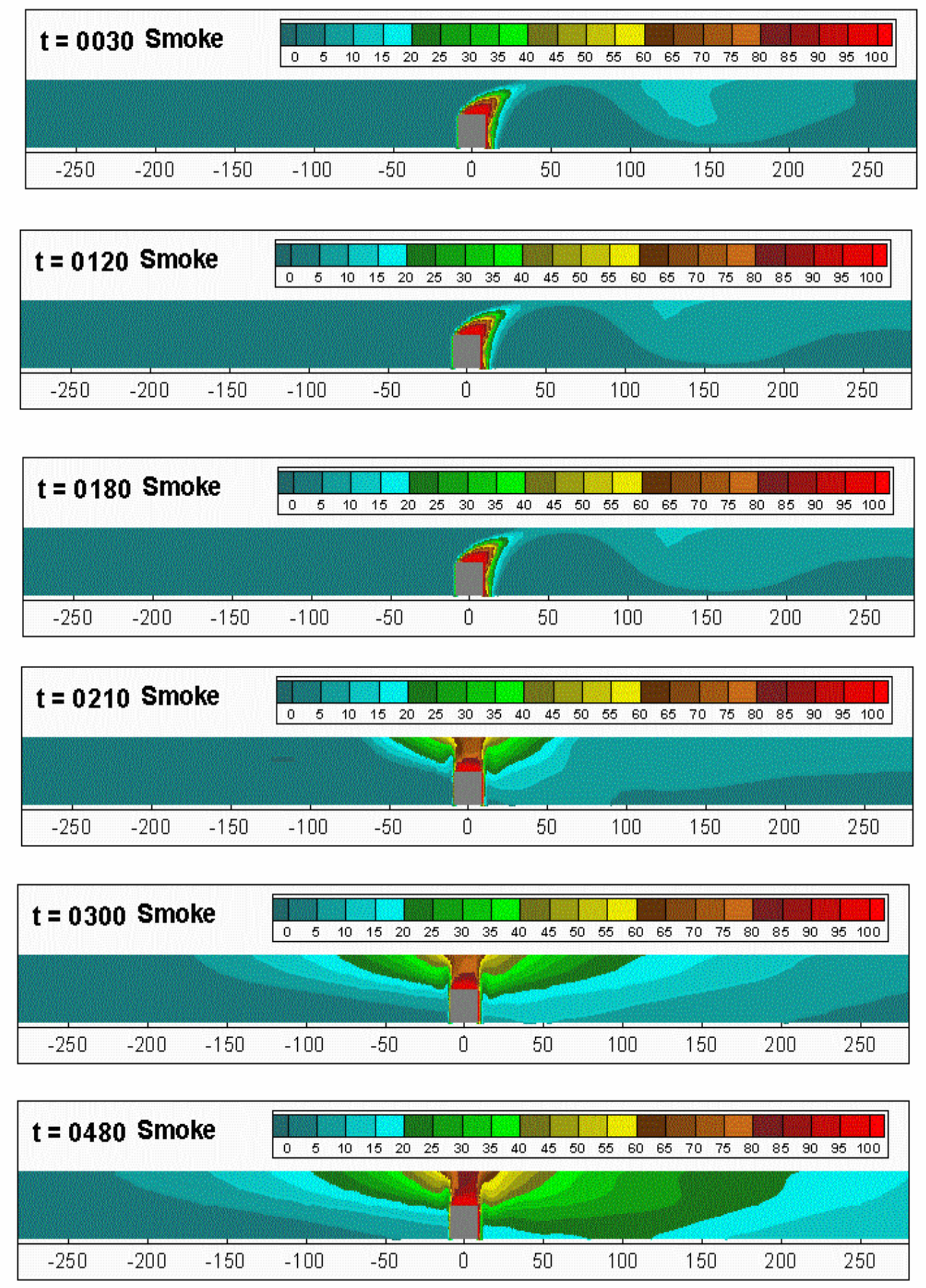

Fig. 10. Smoke concentration in tunnel air from heavy truck fire (west tube, $\mathrm{V}=11.71 \mathrm{~m} / \mathrm{s}$ ). 

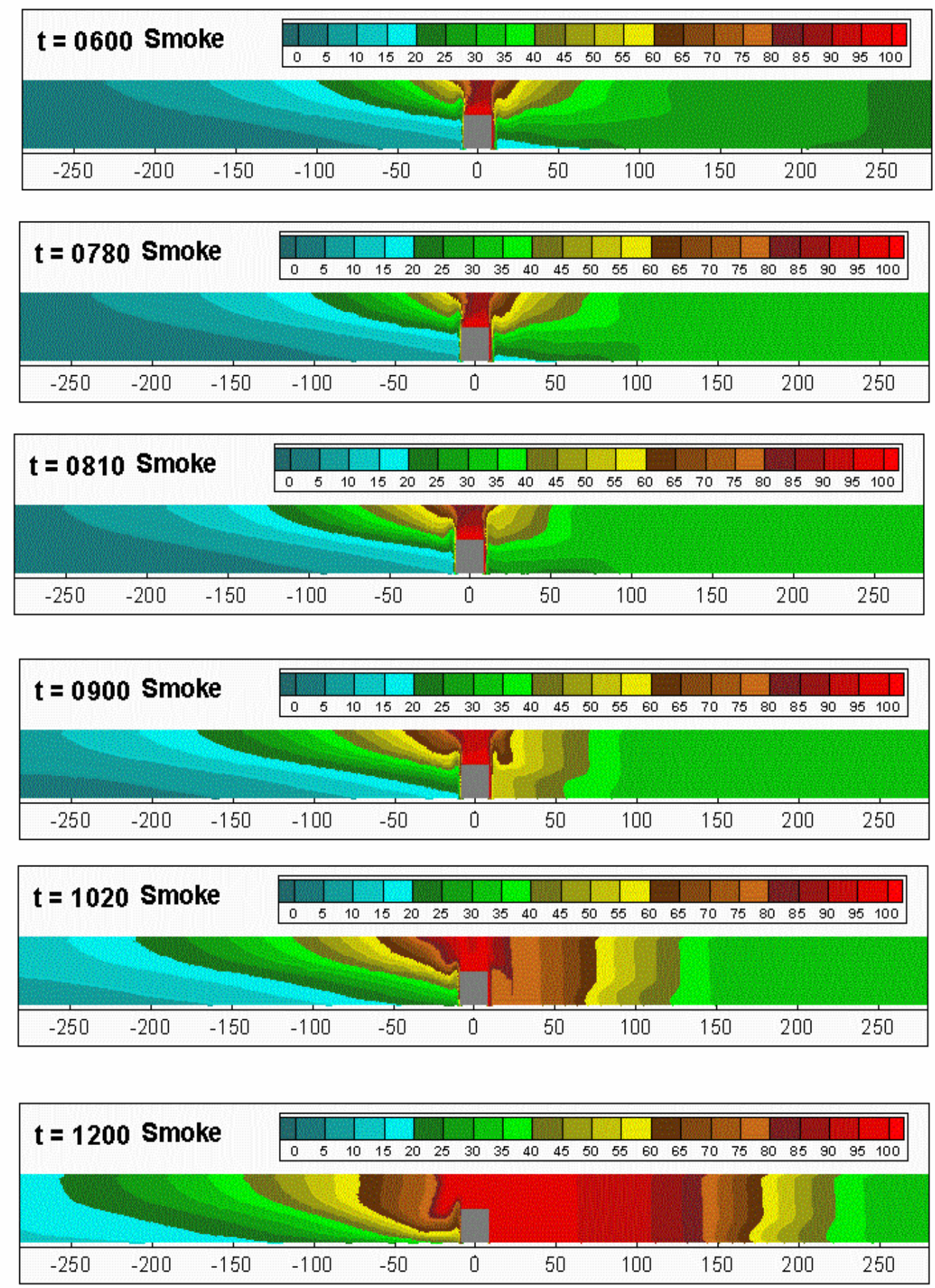

Fig. 11. Smoke concentration from heavy truck fire in west tube $(\mathrm{V}=11.71 \mathrm{~m} / \mathrm{s})$. 